Economics Development Analysis Journal 7 (4) (2018)

\title{
Rantai Nilai Cabai di Lahan Pasir Pantai Kabupaten Kulon Progo
}

\author{
Agus Dwi Nugroho ${ }^{1 凶}$, I Made Yoga Prasada ${ }^{2}$ Saraswati Kirana Putri ${ }^{3}$, Herdiana \\ Anggrasari $^{4}$, Pinjung Nawang Sari ${ }^{5}$
}

Program Studi Ekonomi Pertanian dan Agribisnis, Fakultas Pertanian Universitas Gadjah Mada

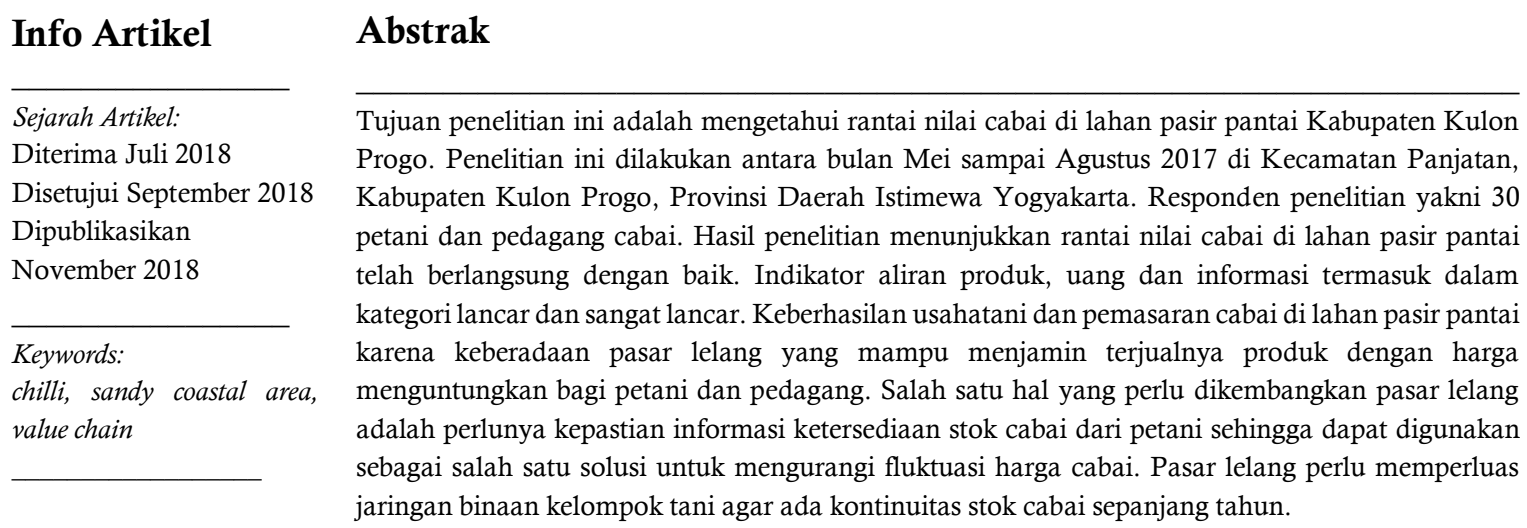

\section{Abstract}

The purpose of this research is to know the value chain of chilli in the sandy coastal area Kulon Progo Regency. This research was conducted between May until August 2017, in Panjatan District, Kulon Progo Regency, Yogyakarta Province. The respondents were 30 farmers and traders. The results showed that the value chain of chilli in the sandy coastal area has been going well. The product, financial and information flow indicators in the smooth and very smooth categories. The success of farming and marketing of chilli in the sandy coastal area because of the existence of the auction market. It's able to guarantee the sale of chilli with the best price for farmers and traders. To develop the auction market, its need for a certainty the availability of chilli stock from farmers so it can be used as a solution to reduce the fluctuation of chilli's price. The auction market needs to expand the network of farmer groups to ensure continuity of chilli stock every year..

(C) 2018 Universitas Negeri Semarang

\footnotetext{
${ }^{\bowtie}$ Alamat korespondensi: ISSN 2252-6965

Gedung L2 Lantai 2 FE Unnes

Kampus Sekaran, Gunungpati, Semarang, 50229

E-mail: agus.dwi.n@mail.ugm.ac.id
} 
Agus Dwi Nugrogo, dkk/ Economics Development Analysis Journal 7 (4) (2018)

\section{PENDAHULUAN}

Ketertinggalan pembangunan pertanian di wilayah marjinal hampir dijumpai di semua aspek, baik biofisik, infrastruktur, kelembagaan usahatani maupun akses informasi untuk petani miskin (Yuwono, 2009). Lahan pasir pantai merupakan wilayah marjinal dengan kesuburan rendah dan berbagai faktor pembatas (Suharta, 2010). Namun dengan semakin terbatasnya lahan pertanian, masyarakat mulai memanfaatkan lahan pasir pantai sebagai kawasan budidaya pertanian. Masyarakat melakukan berbagai upaya untuk meningkatkan kualitas tanah bertekstur pasir di pantai sehingga memenuhi syarat tumbuh tanaman (Barus, dkk, 2013). Hal ini menjadi suatu yang wajar karena wilayah pesisir telah sejak lama dimanfatkaan untuk berbagai aktivitas ekonomi seperti perikanan, pariwisata, pertambangan, pembangkit energi dan lainnya (Pinto, 2015).

Salah satu lahan pasir pantai yang digunakan sebagai kawasan budidaya pertanian adalah wilayah Kabupaten Kulon Progo, Provinsi Daerah Istimewa Yogyakarta (DIY). Wilayah pasir pantai Kulon Progo mampu menghasilkan cabai dan berkontribusi sebesar $72 \%$ terhadap seluruh total produksi cabai di DIY. Budidaya cabai di daerah pasir pantai sangat menguntungkan petani dan memiliki keunggulan kompetitif (Istiyanti, dkk, 2015). Bahkan, cabai merupakan pendapatan tertinggi bagi petani pasir pantai di setiap musim tanam (Widodo, 2015). Meskipun begitu, petani akan selalu menghadapi tantangan diantaranya kepemilikan lahan kecil, biaya produksi tinggi, kurangnya modal untuk investasi, tidak ada fasilitas penyimpanan, keterbatasan teknologi pascapanen dan pembangunan infrastruktur yang buruk serta penetapan harga dominan dilakukan pedagang (Baan, 2014; Dhamon, 2017). Hal tersebut juga menjadi salah satu penyebab tingginya tingkat kemiskinan masyarakat wilayah pesisir Provinsi DIY yang mengindikasikan pola usahatani yang dilaksanakan petani belum cukup berhasil memberikan pendapatan yang optimal (Widodo, 2008; Sari, 2018).

Untuk mengatasi berbagai masalah yang dihadapi petani, maka perlu dilakukan pengelolaan rantai nilai yang baik (ACIAR, 2012). Rantai nilai menggambarkan berbagai kegiatan yang saling terintegrasi dan dibutuhkan untuk mendistribusikan produk atau layanan, dimulai dari konsep awal, melalui fase produksi (melibatkan kombinasi transformasi fisik dan masukan dari berbagai layanan produsen), penyimpanan, pengiriman ke konsumen akhir dan proses setelah produk dipakai sehingga menghubungkan dan mengkoordinasikan produsen, pemroses, pedagang, dan distributor dari sebuah produk (Rofaida, 2012; Kaplinsky, 2013; Yang \& Zhang, 2015).

Pengelolaan rantai nilai yang baik akan mampu meningkatkan nilai tambah komoditas (value added) bagi pelanggan dan keuntungan bagi petani atau industri dengan cara meminimalkan biaya dan waktu dengan efektif dan efisien tanpa mengurangi kualitas produk sehingga pelaku usaha menjadi lebih kompetitif (Baihaqi, dkk, 2014; Mangifera, 2015; Kumar \& Rajeev, 2016). Berdasarkan hal tersebut, maka menjadi suatu hal menarik untuk mempelajari rantai nilai cabai di lahan pasir pantai karena sangat dibutuhkan petani dan belum banyak dipelajari oleh peneliti lain. Tujuan dari penelitian ini adalah mengetahui rantai nilai cabai di lahan pasir pantai Kabupaten Kulon Progo.

\section{METODE PENELITIAN}

Analisis yang digunakan dalam penelitian ini antara lain analisis aliran produk, aliran keuangan dan aliran informasi. Analisis aliran produk dilakukan dengan mengidentifikasi pelaku usaha, peran masingmasing pelaku usaha, serta saluran pemasaran produk. Analisis aliran keuangan yakni dengan mengidentifikasi marjn pemasaran, Marjin pemasaran merupakan selisih harga di tingkat konsumen dan harga di tingkat produsen. Untuk menghitung marjin dari setiap lembaga pemasaran digunakan rumus (Widiastuti \& Harisudin, 2013) :

$$
\mathrm{Mp}=\mathrm{Pr}-\mathrm{Pf} \text { atau } \mathrm{Mp}=\mathrm{Bp}+\mathrm{Kp}
$$

Keterangan:

$\mathrm{Mp} \quad=$ Marjin pemasaran $(\mathrm{Rp} / \mathrm{kg})$

$\mathrm{Pr} \quad=$ Harga di tingkat konsumen $(\mathrm{Rp} / \mathrm{kg})$ 
Pf $\quad=$ Harga di tingkat produsen $(\mathrm{Rp} / \mathrm{kg})$

Analisis aliran informasi dilakukan dengan mengetahui asal usul dan jenis informasi yang diperoleh petani. Analisis selanjutnya adalah skala likert untuk mengetahui kelancaran seluruh aliran dalam rantai nilai cabai di pasir pantai Kulon Progo. Skala likert digunakan untuk mengukur persepsi, pendapat atau sikap seseorang dalam mengahadapi suatu masalah. Skala likert yang digunakan dalam analisis ini terdiri dari beberapa item atau indikator yakni 10 indikator untuk mengukur kelancaran aliran produk cabai, sedangkan pada analisis rantai pasok aliran uang digunakan 9 indikator dan analisis rantai pasok aliran informasi digunakan 14 indikator.

Setiap indikator pada masing-masing aliran rantai pasok dinilai dengan menggunakan skala likert dengan nilai 1 (sangat tidak setuju), 2 (tidak setuju), 3 (raguragu), 4 (setuju), dan 5 (sangat setuju). Setelah nilai dari skala likert diperoleh, maka untuk memastikan bahwa indikator yang digunakan valid dan reliabel, maka nilai pada masing-masing indikator pada masing-masing aliran perlu diuji dahulu validitas dan reabilitasnya. Setelah dinyatakan valid dan reliabel, maka hasil dari skala likert dapat diinterpretasikan sebagai hasil penelitian.

\section{HASIL DAN PEMBAHASAN}

Berdasarkan hasil analisis, lembaga pemasaran yang terlibat dalam aliran produk cabai di daerah pasir pantai meliputi:

Mayoritas petani cabai menjual hasil panen cabai ke pasar lelang. Pasar lelang tersebut berada dalam satu desa dan relatif dekat dengan lahan petani. Petani lahan pasir pantai menjual produksi cabai ke pasar lelang karena efektivitas fungsi pemasaran dari pengelola pasar lelang yang meliputi perencanaan produk, sistem penetapan harga, distribusi fisik, periklanan dan promosi serta

Penjualan yang baik (Rusdiyana, 2015). Hanya sebagian kecil petani yang menjual ke pedagang pengepul. Biasanya petani menjual cabai ke pedagang pengepul pada awal panen karena pasar lelang belum dibuka. Jumlah cabai yang dijual ke pedagang pengepul jauh lebih sedikit dibandingkan cabai yang dijual ke pasar lelang. Pada pasar lelang, cabai yang dikumpulkan dari seluruh petani akan ditawarkan pada pedagang pengepul yang turut serta dalam penawaran. Cabai akan dijual kepada pedagang yang memberikan harga penawaran tertinggi. Petani yang menjual cabai ke pasar lelang rata-rata tidak mengetahui siapa pedagang yang membeli hasil panen mereka.

Petani cabai melaksanakan fungsi pertukaran dan fungsi fisik dalam pemasaran. Fungsi pertukaran dilakukan petani untuk memindahkan kepemilikan cabai ke pasar lelang. Sebelum proses penjualan, petani melakukan fungsi fisik yakni sortasi untuk memilah cabai yang layak dan tidak layak dijual.

Pedagang pengumpul di Kecamatan Panjatan biasanya menggunakan sistem tunda bayar karena jumlah pembelian cabai yang besar melalui pasar lelang dan pedagang biasanya mengalami keterbatasan modal. Petani dapat menerima dana hasil penjualan setelah 1 minggu dari proses transaksi di pasar lelang.

Ada 3 fungsi pemasaran yang dilakukan pedagang pengumpul, yaitu pertukaran, fisik, dan fasilitasi. Fungsi pertukaran meliputi penjualan dan pembelian. Para pedagang pengumpul membeli cabai dari petani kemudian menjual ke pengecer. Pedagang pengumpul melakukan fungsi fisik seperti sortasi, grading, dan transportasi. Setelah membeli cabai dari petani, pedagang pengumpul menyortir cabai sesuai dengan standar tertentu. Kemudian, pedagang pengumpul akan mengirim cabai ke pengecer dan melakukan fungsi pengangkutan. Selama proses ini, ada risiko kerusakan produk yang ditanggung pedagang pengumpul sehingga harus melakukan fungsi fasilitasi. Selain itu, pedagang pengumpul juga melakukan fungsi mengumpulkan informasi pasar mengenai harga berlaku.

Pedagang pengecer adalah agen pemasaran yang berfungsi untuk mendistribusikan produk dari pedagang pengumpul ke konsumen. Pedagang pengecer menjual cabai di pasar tradisional di provinsi DIY. Pedagang pengecer melakukan tiga fungsi pemasaran meliputi pertukaran, fisik, dan fasilitasi. 
Pedagang pengecer melakukan fungsi pertukaran dengan membeli cabai dari pedagang pengumpul dan menjual kepada konsumen. Fungsi fisik yang dilakukan pedagang pengecer meliputi transportasi dan penyimpanan. Fungsi penyimpanan juga dilakukan pedagang pengecer yakni menyimpan cabai yang tidak terjual. Sedangkan fungsi fasilitasi yang dilakukan pedagang pengecer mirip dengan pedagang pengumpul.

Pelaku pemasaran yang ada kemudian membuat beberapa saluran pemasaran. Saluran pemasaran tersebut antara lain : Pertama : Petani $\rightarrow$ Pedagang Pengecer di Pasar Lelang $\rightarrow$ Konsumen

Di saluran pemasaran ini, petani menjual cabai langsung ke pedagang pengecer melalui pasar lelang. Pedagang pengecer kemudian menjual cabai ke konsumen tingkat akhir. Pedagang pengecer biasanya menjual di pasar tradisional sekitar DIY. Persentase total produk yang mengalir dalam saluran pemasaran ini adalah 49,85\%. Petani tidak perlu mengeluarkan biaya pengiriman cabai karena pedagang pengecer langsung mengambil cabai dari petani.

Kedua: Petani $\rightarrow$ Pedagang Pengumpul di Pasar Lelang $\rightarrow$ Pedagang Pengecer $\rightarrow$ Konsumen

Di saluran pemasaran ini, petani menjual cabai ke pedagang pengumpul, utamanya pedagang di pasar lelang. Kemudian pedagang pengumpul menjualnya ke pedagang pengecer dan selanjutnya pedagang pengecer menjual ke konsumen. Pedagang pengecer biasanya menjual cabe melalui pasar tradisional di provinsi DIY, seperti Pasar Giwangan, dan pasar luar DIY. Jenis saluran pemasaran ini dipilih oleh $50,15 \%$ petani. Aliran produksi berlangsung sangat cepat dari produsen ke konsumen. Hal ini sangat penting karena karakteristik produk hotikultura mudah rusak sehingga memerlukan penanganan yang cepat untuk meminimalkan kerugian (Astuti, dkk, 2010). Kualitas cabai yang baik juga dikarenakan petani lahan pasir pantai mampu mengoptimalkan teknologi dan inovasi usahatani (Kusumaningrum, dkk., 2015). Inovasi tersebut dapat berupa pengendalian serangan Organisme Pengganggu Tanaman, pengaturan sistem tanam, penggunaan pupuk organik serta penanganan pasca panen yang tepat dapat meningkatkan mutu hasil dan pendapatan petani (Amiarsi \& Mulyawanti, 2013).

Produk petani dipasarkan langsung ke pedagang pada hari yang sama dengan saat panen. Langkah ini untuk menghindari kerugian petani karena kerusakan hasil panen. Namun sebelumnya, petani melakukan sortasi untuk memisahkan cabai segar dan cabai busuk. Setelah proses penyortiran selesai, petani akan membawa produk ke pasar lelang atau langsung menjualnya ke pedagang dengan sistem timbangan. Petani menjual cabai segar atau tidak melakukan pengolahan hasil. Kondisi ini seperti petani di negara lain yang tidak melakukan upaya penanganan jamur, pengemasan atau penanganan yang benar dan penanganan lainnya (International Labour Organization, 2016).

Pedagang pada prinsipnya langsung memasarkan produk ke berbagai lokasi, mulai dari pasar lokal, hingga pasar luar kota dan luar provinsi, sehingga produk cabai bisa segera didistribusikan ke konsumen akhir. Pedagang melakukan sortasi dan langsung mengemasnya dalam kardus berukuran 30 kilogram yang kemudian langsung dikirim ke lokasi tujuan dengan menggunakan truk.

Aliran produk cabai yang disalurkan dari petani ke konsumen sudah sangat baik dari kondisi fisik sampai transportasi (Tabel 1). Hal ini karena proses sortasi dan grading dilaksankan secara bertahap, dimulai dari kelompok tani sampai dengan pengelola pasar lelang. Salah satu keunggulan cabai pasir pantai adalah ukuran yang besar serta dalam keadaan bersih dibandingkan dengan cabai yang dihasilkan di wilayah sekitarnya. Hal ini sangat penting karena keputusan konsumen membeli cabai merah dipengaruhi keadaan produk, seperti penampakan luar, warna, tidak ada tanda busuk, kebersihan, harga, dan kesegaran (Adiyoga a) dan b), 2011). Dengan berdasarkan analisis aliran produk, maka dapat diperoleh gambaran bahwa cabai merah lahan pasir pantai telah sesuai dengan keinginan konsumen. Namun begitu, petani masih berharap dapat meningkatkan volume cabai yang terjual di pasar lelang. 
Agus Dwi Nugrogo, dkk/ Economics Development Analysis Journal 7 (4) (2018)

Tabel 1 Aliran Produksi Cabai di Lahan Pasir Pantai

\begin{tabular}{llllll}
\hline Keterangan & Interval & Skor & Validitas & Total Skor & Kategori \\
\hline Total penjualan & $0-5$ & 3,79 & $0,019^{\mathrm{b})}$ & 163 & Lancar \\
Berat & $0-5$ & 4,07 & $0,000^{\mathrm{a})}$ & 175 & Sangat Lancar \\
Ukuran & $0-5$ & 4,26 & $0,000^{\mathrm{a})}$ & 183 & Sangat Lancar \\
Bentuk & $0-5$ & 4,14 & $0,000^{\text {a) }}$ & 178 & Sangat Lancar \\
Warna & $0-5$ & 3,86 & $0,000^{\text {a) }}$ & 166 & Lancar \\
Kebersihan & $0-5$ & 4,23 & $0,000^{\text {a) }}$ & 182 & Sangat Lancar \\
Kesegaran & $0-5$ & 3,88 & $0,000^{\text {a) }}$ & 167 & Lancar \\
Pengemasan & $0-5$ & 4,23 & $0,000^{\text {a) }}$ & 182 & Sangat Lancar \\
Sortasi & $0-5$ & 3,91 & $0,000^{\text {a) }}$ & 168 & Lancar \\
Ketersediaan Transportasi & $0-5$ & 4,19 & $0,020^{\text {b) }}$ & 180 & Sangat Lancar \\
\hline
\end{tabular}

Sumber : Analisis data primer, 2017

Keterangan :

a) Signifikan pada $99 \%(\alpha=0,01)$

b) Signifikan pada $95 \%(\alpha=0,05)$

c) Signifikan pada $90 \%(\alpha=0,1)$

d) Tidak signifikan

Dalam saluran pemasaran terdapat perbedaan harga konsumen akhir dengan harga yang diterima petani atau biasa disebut marjin pemasaran. Marjin pemasaran meliputi biaya dan keuntungan tiap lembaga pemasaran. Berdasarkan hasil analisis dapat diketahui saluran pemasaran pertama memiliki nilai marjin pemasaran lebih kecil dibandingkan saluran kedua (Tabel 2).

Hal ini sesuai teori dimana semakin pendek rantai pemasaran maka marjin pemasaran akan rendah dan semakin efisien. Pada saluran pertama, lembaga pemasaran yang terlibat lebih sedikit daripada saluran kedua sehingga biaya dan keuntungan pemasaran juga lebih rendah. Alasan kedua adalah pengiriman cabai dilakukan dalam jumlah besar sehingga mampu menghemat biaya pemasaran atau lebih efisien dan efektif.

Hasil penelitian juga menunjukkan bahwa selisih marjin yang besar antara produsen dengan konsumen disebabkan keuntungan pedagang yang sangat besar. Kondisi ini sejalan dengan penelitian Rum (2011) yang menunjukkan pedagang akan mengambil keuntungan yang besar dalam pemasaran komoditas pertanian. 
Agus Dwi Nugrogo, dkk/ Economics Development Analysis Journal 7 (4) (2018)

Tabel 2 Marjin, Biaya dan Keuntungan Pemasaran Cabai di Kawasan Pasir Pantai

\begin{tabular}{|c|c|c|c|}
\hline No. & Lembaga Pemasaran & Saluran I & Saluran II \\
\hline \multirow[t]{3}{*}{1} & Petani & & \\
\hline & Harga jual (Rp/Kg) & 12.964 & 13.600 \\
\hline & Biaya pemasaran $(\mathrm{Rp} / \mathrm{Kg})$ & 221 & 216 \\
\hline \multirow[t]{6}{*}{2} & Pedagang Pengumpul & & \\
\hline & Harga beli (Rp/Kg) & - & 13.600 \\
\hline & Harga jual (Rp/Kg) & - & 20.500 \\
\hline & Biaya pemasaran $(\mathrm{Rp} / \mathrm{Kg})$ & - & 96 \\
\hline & Keuntungan $(\mathrm{Rp} / \mathrm{Kg})$ & - & 6.804 \\
\hline & Marjin $(\mathrm{Rp} / \mathrm{Kg})$ & - & 6.900 \\
\hline \multirow[t]{7}{*}{3} & Pedagang Pengecer & & \\
\hline & Harga beli (Rp/Kg) & 12.964 & 20.500 \\
\hline & Harga jual (Rp/Kg) & 23.283 & 25.917 \\
\hline & Biaya pemasaran $(\mathrm{Rp} / \mathrm{Kg})$ & 865 & 102 \\
\hline & Keuntungan $(\mathrm{Rp} / \mathrm{Kg})$ & 9.454 & 5.315 \\
\hline & Marjin $(\mathrm{Rp} / \mathrm{Kg})$ & 10.319 & 5.417 \\
\hline & Total Marjin (Rp/Kg) & 10.319 & 12.317 \\
\hline
\end{tabular}

Sumber : Analisis data primer, 2017

Semua indikator aliran uang pada usahatani cabai di lahan pasir pantai memiliki kategori lancar dan sangat lancer (Tabel 3). Hal ini menunjukkan bahwa arus uang pada usahatani cabai tidak ada masalah yang dapat menghambat kelancaran transfer uang dalam supply chain cabai. Tempat transaksi atau tempat penjualan cabai bersifat insidental atau bisa dilakukan di lokasi produsen, pedagang, atau pelelangan.

Lokasi pedagang tidak jauh dari lokasi petani sehingga memudahkan proses jual beli cabai. Semua cabai dari petani akan ditimbang terlebih dahulu sebelum dijual. Setelah produk cabai ditimbang, pembayaran akan dilakukan oleh pedagang kepada petani. Pembayaran dilakukan dengan dua sistem, yaitu cash saat pedagang membeli langsung dari petani atau sistem tunda bayar saat pedagang membeli melalui pasar lelang.

Penundaan pembayaran dilakukan hingga satu minggu sejak produk di pasar lelang terjual. Kedua sistem tersebut dianggap menunjang kelancaran arus uang dalam rantai nilai cabai. Pembayaran transaksi antar sesama pedagang dilakukan dengan sistem tunda bayar karena nilai transaksi cabai sangat besar. Penundaan pembayaran antar pedagang ini dilakukan dalam waktu tiga hari setelah pengiriman.

Petani maupun pedagang mudah mendapatkan bantuan modal dari bank dengan bunga lunak. Model pinjaman dari bank idealnya melalui kelompok tani atau koperasi petani. Hal ini seperti yang diungkapkan Karyani, dkk (2015) yakni pembiayaan pra panen untuk petani cabai merah yang merupakan bagian dari kelompok tani atau anggota koperasi serta pembiayaan perdagangan sesuai kesepakatan kontrak dengan pembeli. 
Agus Dwi Nugrogo, dkk/ Economics Development Analysis Journal 7 (4) (2018)

Tabel 3. Aliran Keuangan Cabai di Kawasan Pasir Pantai

\begin{tabular}{llllll}
\hline Keterangan & Interval & Skor & Validitas & Total Skor & Kategori \\
\hline Tempat Transaksi & $0-5$ & 4,28 & $0,000^{\text {a) }}$ & 184 & Sangat Lancar \\
Jenis Transaksi & $0-5$ & 4,09 & $0,000^{\text {a) }}$ & 176 & Sangat Lancar \\
Cara Pembayaran Transaksi & $0-5$ & 3,86 & $0,000^{\text {a) }}$ & 166 & Lancar \\
Waktu Pembayaran Transaksi & $0-3$ & 1,70 & $0,000^{\text {a) }}$ & 73 & Cukup Lancar \\
Cara Mendapatkan Modal & $0-5$ & 4,09 & $0,000^{\text {a) }}$ & 176 & Sangat Lancar \\
Cara Pembayaran Kredit & $0-5$ & 3,98 & $0,000^{\text {a) }}$ & 171 & Lancar \\
Waktu Pembayaran Kredit & $0-4$ & 3,35 & $0,000^{\text {a) }}$ & 144 & Sangat Lancar \\
$\begin{array}{l}\text { Pembayaran Uang Keamanan } \\
\text { di Pasar }\end{array}$ & $0-4$ & 3,79 & $0,032^{\text {b) }}$ & 163 & Sangat Lancar \\
\hline
\end{tabular}

Sumber : Analisis data primer, 2017

Keterangan :

a) Signifikan pada $99 \%(\alpha=0,01)$

b) Signifikan pada $95 \%(\alpha=0,05)$

c) Signifikan pada $90 \%(\alpha=0,1)$

d) Tidak signifikan

Tabel 4. Aliran Informasi Pemasaran Cabai di Kawasan Pasir Pantai

\begin{tabular}{llllll}
\hline Keterangan & Interval & Skor & Validitas & Total Skor & Kategori \\
\hline Variasi & $0-5$ & 3,74 & $0,000^{\text {a) }}$ & 161 & Lancar \\
Waktu Tanam & $0-5$ & 3,77 & $0,000^{\text {a) }}$ & 162 & Lancar \\
Waktu Panen & $0-5$ & 4,19 & $0,003^{\text {a) }}$ & 180 & Sangat Lancar \\
Pasokan / Produksi & $0-3$ & 2,40 & $0,000^{\text {a) }}$ & 103 & Lancar \\
Permintaan & $0-3$ & 2,23 & $0,000^{\text {a) }}$ & 96 & Lancar \\
Penanganan Pasca Panen & $0-3$ & 2,16 & $0,000^{\text {a) }}$ & 93 & Lancar \\
Harga Pembelian & $0-5$ & 3,70 & $0,000^{\text {a) }}$ & 159 & Lancar \\
Harga Jual & $0-5$ & 3,70 & $0,000^{\text {a) }}$ & 159 & Lancar \\
Kualitas & $0-5$ & 4,02 & $0,000^{\text {a) }}$ & 173 & Sangat Lancar \\
Waktu Pengiriman & $0-3$ & 2,05 & $0,000^{\text {a) }}$ & 88 & Lancar \\
Transportasi & $0-3$ & 2,16 & $0,000^{\text {a) }}$ & 93 & Lancar \\
Jarak ke Tujuan & $0-3$ & 2,23 & $0,000^{\text {a) }}$ & 96 & Lancar \\
Tingkat Kompetisi & $0-3$ & 1,81 & $0,004^{\text {a) }}$ & 78 & Lancar \\
Preferensi & & & & Lancar \\
Pengecer & $0-3$ & 2,02 & $0,000^{\text {a) }}$ & 87 & \\
\hline
\end{tabular}

Sumber : Analisis data primer, 2017

Keterangan :

a) Signifikan pada $99 \%(\alpha=0,01)$

b) Signifikan pada $95 \%(\alpha=0,05)$

c) Signifikan pada $90 \%(\alpha=0,1)$

d) Tidak signifikan

Aliran informasi sangat penting dalam rantai nilai sebab dengan lancarnya aliran informasi, maka kegiatan produksi hingga pemasaran cabai dari tingkat petani hingga konsumen akhir dapat berlangsung dengan baik. Hampir semua indikator aliran informasi memiliki kategori lancar karena setiap informasi dapat diperoleh dengan mudah oleh setiap lembaga 
Agus Dwi Nugrogo, dkk/ Economics Development Analysis Journal 7 (4) (2018)

pemasaran (Tabel 4). Informasi tersebut dapat diidentifikasi melalui pasar lelang, menggunakan alat komunikasi atau dengan bertukar informasi antar pelaku pemasaran.

Waktu panen cabai sangat bervariasi antar petani karena perbedaan waktu tanam dan perbedaan varietas yang digunakan petani. Hal ini mengakibatkan pedagang tidak dapat memperkirakan jumlah produksi atau penawaran dengan tepat. Secara umum, rantai nilai cabai di DIY termasuk sangat lancar sehingga seluruh kegiatan usahatani dan pemasaran cabai tidak mengalami hambatan (Tabel 5). Hal tersebut memberi peluanng bagi pengembangan usahatani cabai yang dapat meningkatkan pendapatan dan kemakmuran pelaku usaha, baik petani maupun pedagang.

Tabel 5. Total Skor Aliran Produk, Keuangan, dan Informasi Pemasaran Cabai di Kawasan Pasir Pantai

\begin{tabular}{|c|c|c|c|c|c|}
\hline No. & Jenis Aliran & Interval Skor & Kategori & Skor & Kategori \\
\hline \multirow{5}{*}{1} & \multirow{5}{*}{ Aliran Produk } & $0-430$ & Tidak Lancar & \multirow{5}{*}{1744} & \multirow{5}{*}{ Sangat Lancar } \\
\hline & & $431-860$ & Kurang Lancar & & \\
\hline & & $861-1290$ & Cukup Lancar & & \\
\hline & & $1291-1720$ & Lancar & & \\
\hline & & $1721-2150$ & Sangat Lancar & & \\
\hline \multirow{5}{*}{2} & \multirow{5}{*}{ Aliran Keuangan } & $0-344$ & Tidak Lancar & \multirow{5}{*}{1417} & \multirow{5}{*}{ Sangat Lancar } \\
\hline & & $345-688$ & Kurang Lancar & & \\
\hline & & $689-1032$ & Cukup Lancar & & \\
\hline & & $1033-1376$ & Lancar & & \\
\hline & & $1377-1720$ & Sangat Lancar & & \\
\hline \multirow{5}{*}{3} & \multirow{5}{*}{ Aliran Informasi } & $0-464$ & Tidak Lancar & \multirow{5}{*}{1728} & \multirow{5}{*}{ Lancar } \\
\hline & & $465-929$ & Kurang Lancar & & \\
\hline & & $930-1393$ & Cukup Lancar & & \\
\hline & & $1394-1858$ & Lancar & & \\
\hline & & $1859-2322$ & Sangat Lancar & & \\
\hline
\end{tabular}

Sumber : Analisis data primer, 2017

Pada analisis per responden diketahui hampir semua responden tidak mengalami masalah terkait aliran produk, uang dan informasi (Tabel 6). Responden tidak mengalami kendala karena petani aktif dalam pertemuan kelompok tani serta berpartisipasi dalam pasar lelang, sehingga dapat mengetahui jumlah produksi, permintaan dan harga dari lembaga pemasaran lainnya. Responden yang menghadapi keadaan informasi kurang lancar karena jarang mengikuti kegiatan kelompok tani maupun pasar lelang. Menurut Kuntadi dan Jamhari, (2012).
Petani di Kecamatan Panjatan merasa harga yang diperoleh di pasar lelang jauh lebih tinggi jika dibanding dengan harga ketika menjual cabai ke pedagang pengepul. Metode lelang mampu memberikan banyak manfaat. Pasar lelang mampu menjamin terjualnya produk dalam jumlah besar dengan harga yang menguntungkan bagi petani dan pedagang. Di dalamnya juga terdapat negosiasi antar pelaku pemasaran (Prabhavathi, et. al, 2013; Devi, $\mathrm{dkk}$, 2015). Selain itu, pasar lelang juga mampu meningkatkan kerja sama anggota sehingga dapat mengembangkan kelompok taninya (Fauziah,2017) 
Agus Dwi Nugrogo, dkk/ Economics Development Analysis Journal 7 (4) (2018)

Tabel 6. Distribusi Responden Berdasarkan Nilai Aliran Produk, Keuangan dan Informasi Pemasaran Cabai di Wilayah Pasir pantai

\begin{tabular}{llccc}
\hline No & Kategori & Aliran Produk (\%) & Aliran Keuangan (\%) & Aliran Informasi (\%) \\
\hline 1 & Tidak Lancar & 0,00 & 0,00 & 0,00 \\
2 & Kurang Lancar & 0,00 & 0,00 & 0,00 \\
3 & Cukup Lancar & 0,00 & 0,00 & 20,93 \\
4 & Lancar & 55,81 & 53,49 & 48,84 \\
5 & Sangat Lancar & 44,19 & 46,51 & 30,23 \\
\hline Total & & 100,00 & 100,00 & 100,00 \\
\hline
\end{tabular}

Sumber : Analisis data primer, 2017

\section{SIMPULAN}

Rantai nilai cabai di lahan pasir pantai telah berlangsung dengan baik. Indikator aliran produk, uang dan informasi telah termasuk dalam kategori lancar dan sangat lancar. Keberhasilan usahatani dan pemasaran dan pemasaran cabai di lahan pasir pantai karena keberadaan pasar lelang di Kecamatan Panjatan. Pasar lelang di lahan pasir pantai mampu menjamin terjualnya produk dengan harga yang menguntungkan bagi petani dan pedagang. Salah satu hal yang perlu dikembangkan dalam pasar lelang adalah perlunya kepastian informasi ketersediaan stok cabai dari petani sehingga dapat digunakan sebagai salah satu solusi untuk mengurangi fluktuasi harga cabai. Pasar lelang perlu memperluas jaringan binaan kelompok tani agar ada kontinuitas stok cabai sepanjang tahun.

\section{DAFTAR PUSTAKA}

ACIAR. (2012). Membuat rantai nilai lebih berpihak pada kaum miskin buku pegangan bagi praktisi analisis rantai nilai. Jakarta : Tabros.

Adiyoga, $\mathrm{W}^{\mathrm{a})}$. (2011). Faktor-faktor yang mempengaruhi perilaku dan keputusan konsumen untuk membeli kentang, bawang merah, dan cabai merah. J. Hort, 21(3), 280-294.

Adiyoga, $\mathrm{W}^{\mathrm{b})}$. (2011). Segmentasi konsumen kentang, bawang merah, dan cabai merah berdasarkan peubah sosio-demografis dan kepentingan kriteria produk. J. Hort, 21(4), 353-371.
Amiarsi, D \& Mulyanti, I. (2013). Pengaruh metode pembekuan terhadap karakteristik irisan buah mangga beku selama penyimpanan (effect of freezing method on characteristic of fruit slice of mango during storage). J.Hort, 23(3), 255-262.

Astuti, R., Marimin., Poerwanto, R., Machfud \& Arkeman, Y. (2010). Kebutuhan dan struktur kelembagaan rantai pasok manggis. Jurnal Manajemen Bisnis Integritas, 3(1), 99-115.

Baan, D. G. (2014). Analysis of chilli pepper value chain: a case study of kpando torkor irrigation scheme in the Volta Region of Ghana. Wageningen : Agricultural Production Chain Management Department, Wageningen University,

Baihaqi, A., Ahmad, H. H., Romano \& Yulianda, A. (2014). Analisis rantai nilai dan nilai tambah kakao petani di Kecamatan Paya Bakong Dan Geurudong Pase Kabupaten Aceh Utara. Agrisep, 15(2), 28-35.

Barus, M., Rogomulyo, R \& Trisnowati, S. (2013). Pengaruh takaran pupuk kandang terhadap pertumbuhan dan hasil wijen (Sesamum indicum L) di lahan pasir pantai. Vegetalika, 2(4), 45-54.

Devi, P., Harsoyo \& Subejo. (2015). Keefektifan lembaga pasar lelang cabai merah di Kecamatan Panjatan, Kabupaten Kulon Progo. Jurnal Agro Ekonomi, 26(2), 139-149.

Dhamon, O, B. (2017). Analisis rantai nilai komoditas cabai merah di Agrowisata Desa Candi Kecamatan Bandungan Kabupaten Semarang. Economics Development Analysis Journal, 6(4), 403-411.

Fauziah, F. (2017). Respons petani lahan pasir pantai terhadap pemasaran sistem lelang cabai di Kecamatan Panjatan Kabupaten Kulon Progo. Yogyakarta : Prosiding Seminar Nasional 
Masyarakat Biodiversitas Indonesia, 3, pp. 9498. doi: $10.13057 / \mathrm{psnmbi} / \mathrm{m} 030116$.

International Labour Organization. (2016). Chilli value chain analysis and upgrading strategy : Southern Shan State and Mandalay Region, Myanmar. Yangon : ILO.

Istiyanti, E., Khasanah, U. \& Anjarwati, A. (2015). Pengembangan usahatani cabai merah di lahan pasir pantai Kecamatan Temon Kabupaten Kulon Progo. AGRARIS: Journal of Agribusiness and Rural Development Research, 1(1), 6-11. doi: 10.18196/agr.112.

Kaplinsky, R. (2013). Global value chains, where they came from, where they are going and why this is important. London : The Open University,

Karyani, T., Renaldi, E., Sadeli, A. H \& Utami, H. N. (2015). Design of supply chain financing model of red chilli commodity with structured market orientation. International Journal of Applied Business and Economic Research, 13(7), 61876200.

Kumar, D \& Rajeev PV. (2016). Value chain : a conceptual framework. International Journal of Engineering and Management Science, 7(1), 7477. Available at: http://scienceandnature.org/IJEMS-Vol7(1)Jan2016/IJEMS Vol7(1)-12.pdf.

Kuntadi, E. B \& Jamhari. (2012). Efisiensi pemasaran cabai merah melalui pasar lelang spot di Kabupaten Kulon Progo, Yogyakarta. Jurnal Sosial Ekonomi Pertanian, 1(1), 95-101.

Kusumaningrum, Foor, J. Z \& Mustafa, D. (2015). Social quality masyarakat lahan pasir pantai pada aspek social empowerment di Kecamatan Panjatan Kabupaten Kulon Progo (Social quality of sand land community on social aspect of empowerment in Panjatan sub-district, Kulon Progo Regency). Agriekonomika, 4(1), 1-9.

Mangifera, L. (2015). Analisis rantai nilai (value chain) pada produk batik tulis di Surakarta. Benefit Jurnal Manajemen dan Bisnis, 19(1), 24-33.

Pinto, Z. (2015). Kajian perilaku masyarakat pesisir yang mengakibatkan kerusakan lingkungan (studi kasus di Pantai Kuwaru, Desa Poncosari, Kecamatan Srandakan, Kabupaten Bantul, Provinsi DIY. Jurnal Wilayah dan Lingkungan, 3(3)

163-174. http://dx.doi.org/10.14710.jwl.3.3.163-174.
Prabhavathi, Y., Krishna, N. T., \& Seema, D. (2013). Analysis of supply chain of spices in India: A case study of red chillies. International Journal of Scientific and Research Publications, 3(9), 1-4. Available at: http://www.ijsrp.org/researchpaper-0913/ijsrp-p21101.pdf.

Rofaida, R. (2012). Analisis dan strategi upgrading rantai nilai (value chain management) pada industri susu di Kabupaten Bandung Barat. Jurnal Riset Manajemen, 1(1), 59-71.

Rum, M. (2011). Analisis marjin pemasaran dan sensitivitas cabai besar di Kabupaten Malang. Embryo, 8(2), 133-141.

Rusdiyana, E. (2015). Manajemen kelembagaan pasar lelang dalam memfasilitasi pemasaran cabai kelompok tani lahan pasir pantai Kecamatan Panjatan, Kabupaten Kulon Progo. Jurnal Sungkai, 3(2), 49-64.

Sari, N. I. (2018). Determinan tingkat kemiskinan di Daerah Istimewa Yogyakarta tahun 2007 - 2014. Economics Development Analysis Journal, 7(2), 128-136.

Suharta, N. (2010). Karakteristik dan permasalahan tanah marginal dari batuan sedimen masam di Kalimantan. Jurnal Litbang Pertanian, 29(4), 139-146.

Widiastuti, N. U. R. \& Harisudin, M. (2013). Saluran dan marjin pemasaran jagung di Kabupaten Grobogan. SEPA, 9(2), 231-240.

Widodo, A. S. (2015). Pendapatan dan produksi potensial usahatani konservasi lahan pantai di Kabupaten Bantul. AGRARIS: Journal of Agribusiness and Rural Development Research, 1(1), 1-5. doi: 10.18196/agr.111. (2008). Kajian usahatani lahan pasir pantai di Kabupaten Bantul. Bogor : Seminar Nasional Dinamika Pembangunan Pertanian dan Perdesaan Tantangan dan Peluang bagi Peningkatan Kesejahteraan Petani. 19 November 2008.

Yang, H. \& Zhang, Y. (2015). Online marketing strategy for agricultural supply chain and regional economic growth based on e-commerce perspective. International Journal of Security and its Applications, 9(10) : 323-332. doi: 10.14257/ijsia.2015.9.10.29.

Yuwono, N. W. (2009). Membangun kesuburan tanah di lahan marjinal. Jurnal Ilmu Tanah dan Lingkungan, 9(2), 137-141. 